\title{
DISPROPORTIONATION OF ETHYLBENZENE OVER SAPO-40
}

J.P. Lourenço $^{(1)}$, M.F. Ribeiro ${ }^{(1)^{*}}$, F. Ramôa Ribeiro ${ }^{(1)}$, J. Rocha ${ }^{(2)}$, Z. Gabelica ${ }^{(3)}$

${ }^{(1)}$ Instituto Superior Técnico, Departamento de Engenharia Química, 1096 Lisboa Codex, Portugal

${ }^{(2)}$ Universidade de Aveiro, Departamento de Química, 3800 Aveiro, Portugal

${ }^{(3)}$ Facultés Universitaires N. D. de la Paix, Département de Chimie, B-5000 Namur, Belgium

SAPO-40 exhibits strong acid sites, which catalyse the reaction of disproportionation of ethylbenzene. The distribution of diethylbenzene isomers suggests a high void volume in the structure of this molecular sieve.

KEYWORDS: SAPO-40, Ethylbenzene disproportionation, Acidity

\section{INTRODUCTION}

SAPO-40, a silicoaluminophosphate with a structure not topologically related with any aluminosilicate zeolite, was synthesised for the first time in 1984 by Lok and co-workers [1]. Recently, a synthesis procedure leading to pure SAPO40 was developed and the structure of this material was established by crystallographic methods. The framework topology (designated AFR by the International Zeolite Association) consists of saddle-shaped 12-membered rings forming channels parallel to the c-axis and 8-membered rings channels parallel to the b-axis. These channels, with free diameters of 6.7 and $3.8 \AA$ respectively, intersect to form a two-dimensional system. The third direction is blocked by a wall of 4- and 6- rings [2].

The acidity of this material has been related with the silicon content and the distribution of this element in the framework. The high activity of SAPO-40 in the cracking of n-heptane [3] reflects these two factors, the second, probably being the most important.

\footnotetext{
Corresponding author
} 
The aim of this work is to study the behaviour of a SAPO-40 sample with high silicon content on the reaction of disproportionation of ethylbenzene, which gives information on the acidity and porosity of the catalyst.

\section{EXPERIMENTAL}

The SAPO-40 sample was synthesised hydrothermally according to the procedure described by N. Dumont et al. [2]. It was characterized by powder XRD, SEM, EDX and MAS NMR as described previously [3]. The composition, determined by EDX, in the general formula $\mathrm{TO}_{2}$ is $\left(\mathrm{Si}_{0.12} \mathrm{Al}_{0.48} \mathrm{P}_{40}\right) \mathrm{O}_{2}$. No other crystalline or amorphous phase is seen by XRD and SEM, mixed with the AFR phase.

Two samples of well known zeolites were used for comparison in the catalytic tests: USHY purchased from UOP with a $\mathrm{Si} / \mathrm{Al}$ ratio of 4.5 and HZSM-5 from CONTEKA with a $\mathrm{Si} / \mathrm{Al}$ ratio of 27 and crystal morphology of spherulites (size of about $0.3 \times 0.1 \mu \mathrm{m}$ ).

In order to perform ammonia TPD experiments on the SAPO-40 sample, 200 $\mathrm{mg}$ of powder were calcined in situ at $550{ }^{\circ} \mathrm{C}$ under dry air. After purging with helium, a mixture of ammonia and helium ( $0.2 \%$ of ammonia) was adsorbed at $200{ }^{\circ} \mathrm{C}$ for ca. $16 \mathrm{~h}$. The desorption started, after a purge with helium, at a rate of $5{ }^{\circ} \mathrm{C} / \mathrm{min}$. A thermal conductivity detector was used to detect the ammonia desorbed.

Before the catalytic tests, the SAPO-40 sample was calcined in situ at $550{ }^{\circ} \mathrm{C}$ under dry air to remove the template. The other zeolites were submitted to a pretreatment under nitrogen at $450{ }^{\circ} \mathrm{C}$. The catalytic tests were carried out using ethylbenzene (Aldrich $99 \%$ ) at $350{ }^{\circ} \mathrm{C}, 1 \mathrm{bar}$, WHSV $=17.4 \mathrm{~h}^{-1}$ and $\mathrm{N}_{2} / \mathrm{HC}=$ 15. The reaction products were analysed by gas chromatography and the coke content was determined by thermogravimetry. 


\section{RESULTS AND DISCUSSION}

The ${ }^{27} \mathrm{Al}$ and ${ }^{31} \mathrm{P}$ NMR spectra are similar to those reported by N. Dumont et al. [2]. Figure 1 displays the ${ }^{29} \mathrm{Si}$ spectrum obtained with this sample, which clearly shows the heterogeneity in the framework distribution of silicon. The peak at ca. - $90.1 \mathrm{ppm}$ is commonly assigned to the $\mathrm{Si}(4 \mathrm{Al})$ configuration in a SAPO-region. The specific assignment of the other signals is difficult, however, it has been understood as the result of the formation of silicon islands, which can give the configurations $\mathrm{Si}(\mathrm{nAl})(\mathrm{n} \leq 4)[3]$.

Figure 2 displays the ammonia TPD curve obtained with this SAPO-40 sample. The curve shows the presence of one broad desorption peak at ca. 310 ${ }^{\circ} \mathrm{C}$ with a shoulder at ca. $380{ }^{\circ} \mathrm{C}$. These different acid sites (ranging from medium to strong acidity) are the result of the heterogeneity in the distribution of silicon, which has been suggested to generate strong acid sites at the borders of the silicon islands [4].

Disproportionation of ethylbenzene into benzene and diethylbenzenes has been used as model reaction to characterize zeolite catalysts $[5,6]$. The evolution of the catalytic activity of SAPO-40 with time on stream in this reaction is plotted in figure 3 and compared to that of HZSM-5 and USHY.

Not any significant deactivation is observed on HZSM-5 oppositely to SAPO40 and USHY, which show a severe deactivation due to coke deposition.

The high catalytic activity of SAPO-40 is probably related with the high acidity of this material, already suggested by ammonia TPD and cracking of $n$ heptane [3].

Table 1 shows the formation of products other than those resulting from the pure disproportionation (benzene and diethylbenzene), indicating that dealkylation also occurs. Ethylene resulting from dealkylation undergoes secondary reactions: oligomerization with formation of aliphatic $\mathrm{C}_{3}-\mathrm{C}_{8}$ products and a low amount of aromatics. Consequently, dealkylation contributes significantly to the catalyst deactivation.

Comparing SAPO-40 and HZSM-5, we observe that transformation of ethylene into heavier compounds was favoured on SAPO-40, due to diffusional constraints in the structure of HZSM-5.

The difference of available space between these two structures is well evidenced by the diethylbenzene isomers distribution. This distribution is similar on the SAPO-40 and USHY samples and is closer to the thermodynamic equilibrium than that measured on HZSM-5. This indicates that, in SAPO-40 and USHY catalysts, no constraints exist to the formation or diffusion of these 
compounds. By contrast, HZSM-5 shows the para-selectivity characteristic of its structure. The open structure of SAPO-40 was also confirmed using $m$-xylene isomerization as test reaction [8].

\section{CONCLUSION}

The results of disproportionation of ethylbenzene and ammonia TPD confirm that the silicoaluminophosphate SAPO-40 can be prepared with a high acidity, comparable to traditional zeolites. The distribution of the diethylbenzene isomers accounts well for its open structure.

\section{ACKNOWLEDGEMENTS}

This work was partially supported by JNICT under research contract STRDA /C/CTM/602/92. Financial support by "Project Science 12/M/90" for acquisition of a RXD apparatus is gratefully acknowledged. We thank IMAT/Aveiro for access to the solid-state NMR facility.

\section{REFERENCES}

[1] - B.M. Lok, C.A. Messina, R.L. Patton, R.T. Gajek, T.R. Cannan, E.M. Flanigen: U.S. Pat., 4,440,871 (1984).

[2] - N. Dumont, Z. Gabelica, E.G. Derouane, L.B. McCusker: Microporous Mater., 1, 149 (1993).

[3] - J.P. Lourenço, M.F. Ribeiro, F.R. Ribeiro, J. Rocha, Z. Gabelica, N. Dumont, E.G. Derouane: Studies in Surface Science and Catalysis, 84, 867 (1994).

[4] - J.A. Martens, C. Janssens, P.J. Grobet, H.K. Beyer, P.A. Jacobs: Studies in Surface Science Catalysis, 49 A, 215 (1988).

[5] - H.G. Karge, J. Ladebeck, Z. Sarbak, K. Hatada: Zeolites, 2, 94 (1982).

[6] - R. Kumar, S. Ernst, G.T. Kokotailo, J. Weitkamp: Studies in Surface Science and Catalysis, 37, 451 (1988). 
[7] - T.E. Dauber, R.P. Danner: Physical and Thermodynamic Properties of Pure Chemicals - Data Compilation, National Standards - Reference System, AICHE, Taylor and Francis, Washington, 1994.

[8] - J.P. Lourenço, M.F. Ribeiro, F. Ramôa Ribeiro, J. Rocha, Z. Gabelica: Appl. Catal., in press. 


\section{Figure Captions}

Figure 1. ${ }^{29} \mathrm{Si}$ NMR spectrum of SAPO-40

Figure 2. Ammonia TPD on SAPO-40

Figure 3. Change of the conversion of ethylbenzene with time on stream: (-) USHY, (^) SAPO-40 and (O) HZSM-5. 
Table 1

Initial activity ( $\mathrm{t}=6 \mathrm{~min}$.) and selectivity of the samples tested in the disproportionation of ethylbenzene

\begin{tabular}{|c|c|c|c|c|}
\hline \multirow{3}{*}{\multicolumn{2}{|c|}{$\begin{array}{l}\text { Ethylb. conv. (\%) } \\
\text { Prod. dist.(mol. \%) }\end{array}$}} & SAPO-40 & USHY & HZSM-5 \\
\hline & & 13.0 & 27.6 & 7.7 \\
\hline & & & & \\
\hline \multicolumn{2}{|c|}{$\mathrm{C}_{2}-\mathrm{C}_{8}$ compounds } & 10.6 & 19.4 & 14.4 \\
\hline \multicolumn{2}{|c|}{ Benzene } & 58.5 & 44.7 & 45.0 \\
\hline \multicolumn{2}{|c|}{ Toluene } & 2.1 & 7.2 & 0.9 \\
\hline \multicolumn{2}{|c|}{ Ethyltoluene } & 1.2 & 5.5 & 0.7 \\
\hline \multicolumn{2}{|c|}{ Diethylbenzene } & 27.6 & 23.2 & 39.0 \\
\hline \multicolumn{5}{|c|}{ Diethylb. dist. (mol. \%) } \\
\hline para & $26.0^{a}$ & 27.9 & 30.2 & 38.2 \\
\hline meta & $60.5^{a}$ & 65.2 & 62.9 & 60.0 \\
\hline ortho & $13.5^{a}$ & 6.9 & 6.9 & 1.8 \\
\hline Coke $^{b}$ & & 2.9 & 13.2 & 1.7 \\
\hline
\end{tabular}

(a) values of thermodynamic equilibrium calculated at $350^{\circ} \mathrm{C}$ using thermodynamic data [7].

(b) coke determined after 90 min. on stream. 


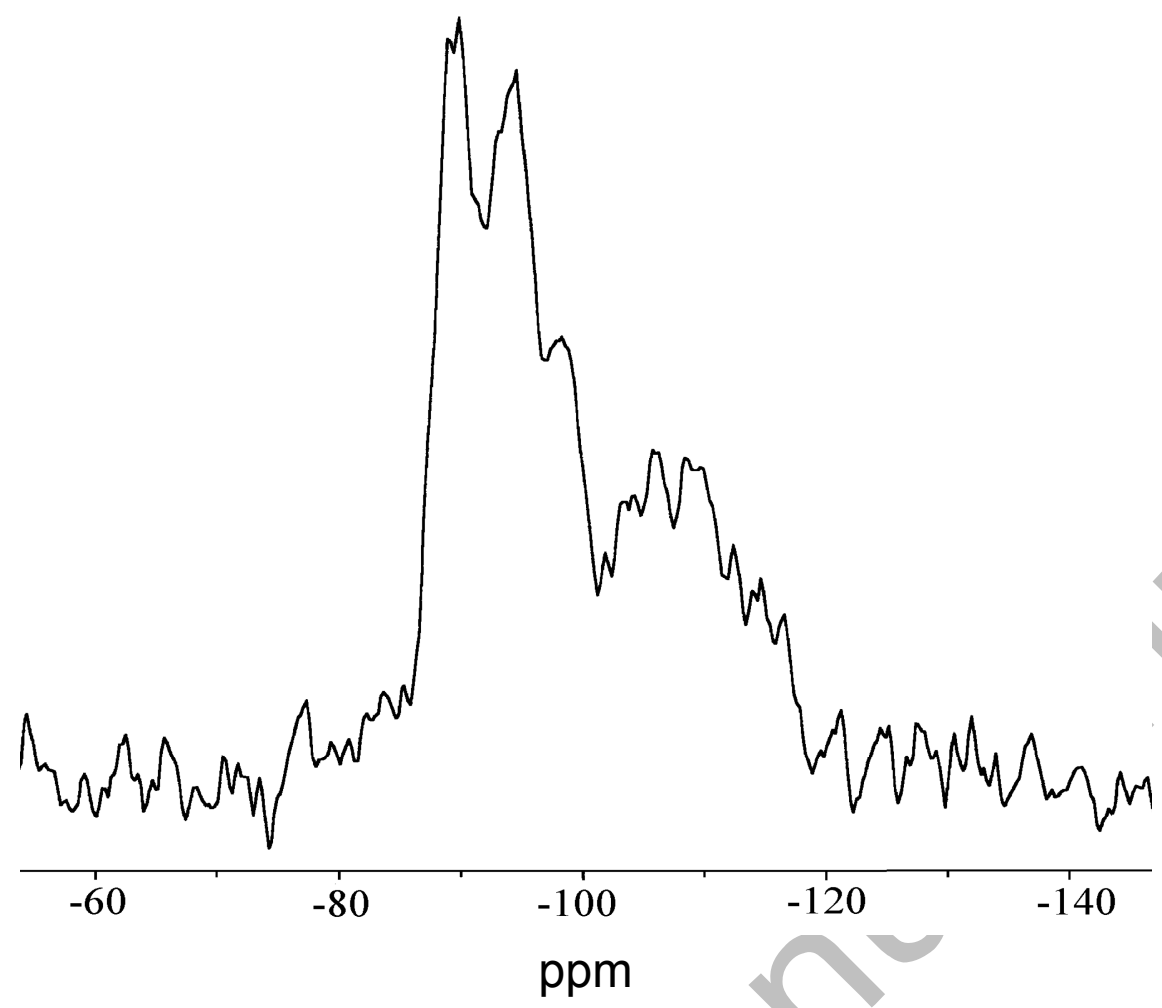

Figure 1

J. P. Lourenço et al. 




Figure 2

J. P. Lourenço et al. 


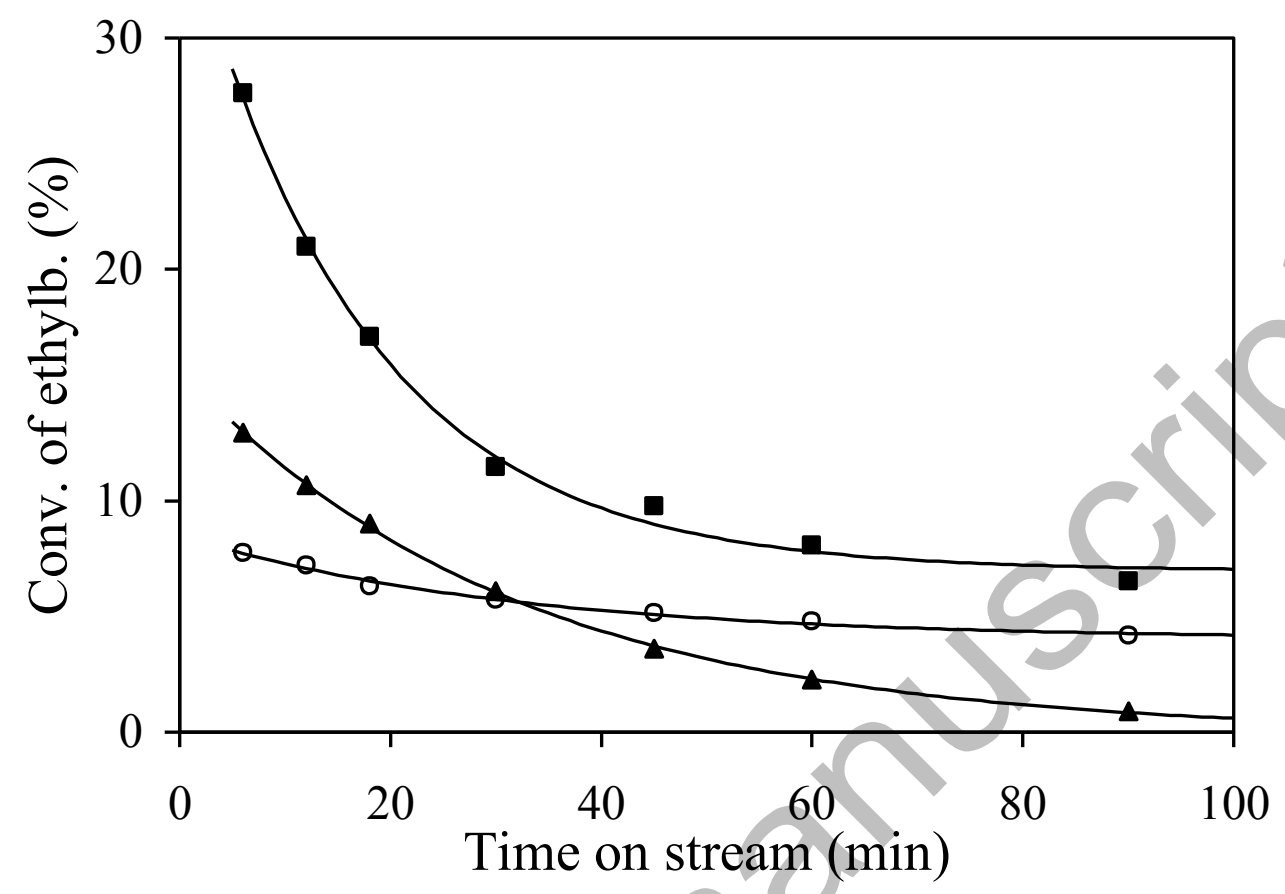

Figure 3

J. P. Lourenço et al. 